\title{
Corrosive Esophageal Injury due to a Commercial Vinegar Beverage in an Adolescent
}

\author{
Jiyeon Chang', Sang Eun Han', Seung Sam Paik² and Yong Joo Kim' \\ Department of ${ }^{1}$ Pediatrics, ${ }^{2}$ Pathology, Hanyang University, College of Medicine, Seoul, Korea
}

\begin{abstract}
Although gastroesophageal damage is commonly induced by accidental drinking of a strong acid or alkali, damage due to the consumption of a vinegar beverage is not well known. We report a case of corrosive esophageal ulcer found in an adolescent consuming a vinegar drink daily. A 15 -year-old male visited the emergency room presenting with hematemesis and severe epigastric pain. Multiple longitudinal ulcers, concurrent mucosal hemorrhage, and denuded mucosa were noted in the whole of the esophagus via an endoscopic examination. He had been drinking a vinegar beverage daily without sufficient dilution. The patient was treated with corticosteroid, antibiotic therapy, and mucosa protecting alginate medication and was asked to fast for a week. The follow-up endoscopy showed improvement of the esophageal injuries. Overall, continuous consumption of a vinegar beverage can result in acidic burns and destruction of the surface of the upper gastrointestinal tract. Therefore, vinegar beverages should be considered as corrosive agents. Clin Endosc 2020;53:366-369
\end{abstract}

Key Words: Acid beverage; Adolescent; Caustic; Corrosive esophagitis

\section{INTRODUCTION}

Although gastroesophageal damage is commonly induced by accidental drinking of a strong acid or strong alkali, damage due to the consumption of a commercial vinegar beverage is not well known. There have been reports of esophageal injury due to the consumption of apple cider vinegar, though it is more strongly acidic than a vinegar beverage. ${ }^{1,2}$ Diverse vinegar beverages are becoming popular and being widely consumed with little evidence with regards to health benefits. Various vinegar beverages are commercially available in the market with $\mathrm{pH}$ values usually below 5.51 . Vinegar drinks are drawing attention as a health solution in everyday diet,

Received: March 18, 2019 Revised: May 17, 2019

Accepted: June 7, 2019

Correspondence: Yong Joo Kim

Department of Pediatrics, Hanyang University, College of Medicine, 222 Wangsimni-ro, Seongdong-gu, Seoul 04763, Korea

Tel: +82-2-2290-8390, Fax: +82-2-2297-2380, E-mail: kyjoo@hanyang.ac.kr ORCID: https://orcid.org/0000-0002-2654-5397

(c) This is an Open Access article distributed under the terms of the Creative Commons Attribution Non-Commercial License (http://creativecommons.org/ licenses/by-nc/3.0) which permits unrestricted non-commercial use, distribution, and reproduction in any medium, provided the original work is properly cited. though there has been no definite clinical evidence in this regard. Because of their acidity, overconsumption of vinegar beverages can result in damage to the gastrointestinal tract. We report a case of corrosive esophageal ulcer that was found in an adolescent consuming a vinegar drink daily.

\section{CASE REPORT}

A 15-year-old boy presented with severe pain at the substernal and epigastric areas with tenderness, vomiting, and hematemesis for 2 weeks. He was hemodynamically stable, with a clear mental state. He had been habitually drinking more than half a cup (100-150 mL) of a pomegranate-fermented vinegar beverage with no sufficient dilution every morning for 1 month. The acidity of this beverage was $2.7 \%$ with a $\mathrm{pH}$ of 2.6, and it was composed of acetic acid (35\%), citric acid $(60 \%)$, and maleic acid (5\%) in the form of organic acids. The manufacturer recommended a 3:1 dilution of water and vinegar before drinking.

Initial laboratory tests showed mild leukocytosis $\left(20,700 / \mathrm{mm}^{3}\right)$ with $79 \%$ segmented neutrophils, $8 \%$ lymphocytes, and $11 \%$ 
monocytes. C-reactive protein was elevated to $9.81 \mathrm{mg} / \mathrm{dL}$, and the initial hemoglobin level was $16.1 \mathrm{~g} / \mathrm{dL}$. Other laboratory findings including coagulation test and electrolytes were normal. Contrast-enhanced chest and abdomen computed tomography (CT) was performed and swelling in the distal esophagus and gastric cardia was noted (Fig. 1).

The esophagogastroduodenoscopy showed multiple deep and longitudinal ulcers with concurrent hemorrhage and denudation along the entire esophagus (Fig. 2A). In the area where cardia swelling was noted on CT, findings of verrucous gastritis were observed via gastrointestinal endoscopy without any acute mucosal changes. Furthermore, the upper gastric body showed the same findings. An esophageal pathologic examination showed no fungal, cytomegalovirus, or herpes virus infection, but acute ulceration with infiltration of neutrophils and eosinophils was noted (Fig. 3). Cytomegalovirus, herpes simplex virus, and tuberculosis tests were negative. Immunoglobulin (IgG, IgA, IgM, and IgD), complement 3, complement 4, and $\mathrm{CH} 50$ levels were also within normal ranges. Immunoglobulin $\mathrm{E}$ was elevated to $862.2 \mathrm{IU} / \mathrm{mL}$, which was thought to be related to his chronic allergic rhinitis. A nasogastric tube was inserted for one week for enteral feeding. Systemic corticosteroid therapy (dexamethasone, $0.1 \mathrm{mg} / \mathrm{kg} /$ day for 1 week) was prescribed and then tapered. Cefamezin, a first-generation cephalosporin, was administered every 8 hours to a total of $50 \mathrm{mg} / \mathrm{kg} /$ day. His C-reactive protein level decreased to $0.84 \mathrm{mg} / \mathrm{dL}$ on the third day of admission. Follow-up endoscopy, performed on the 7th day of admission,
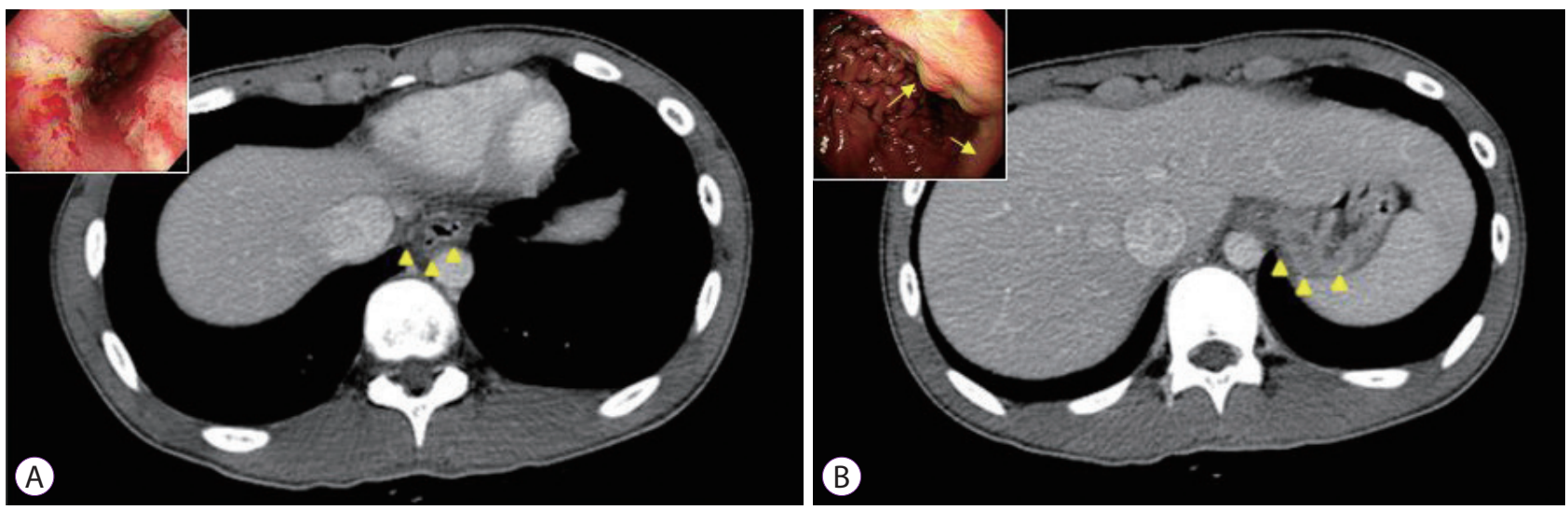

Fig. 1. Contrast enhanced abdominal computed tomography image of the patient. The image showed swelling in the distal esophagus (A, arrowheads) and gastric cardia ( $B$, arrowheads). The swelling of the esophagus was later documented to be severely ulcerated with a hemorrhagic mucosal injury (A inlet) and that of gastric cardia to be verrucous gastritis with chronic inflammation ( $\mathrm{B}$ inlet, arrows).
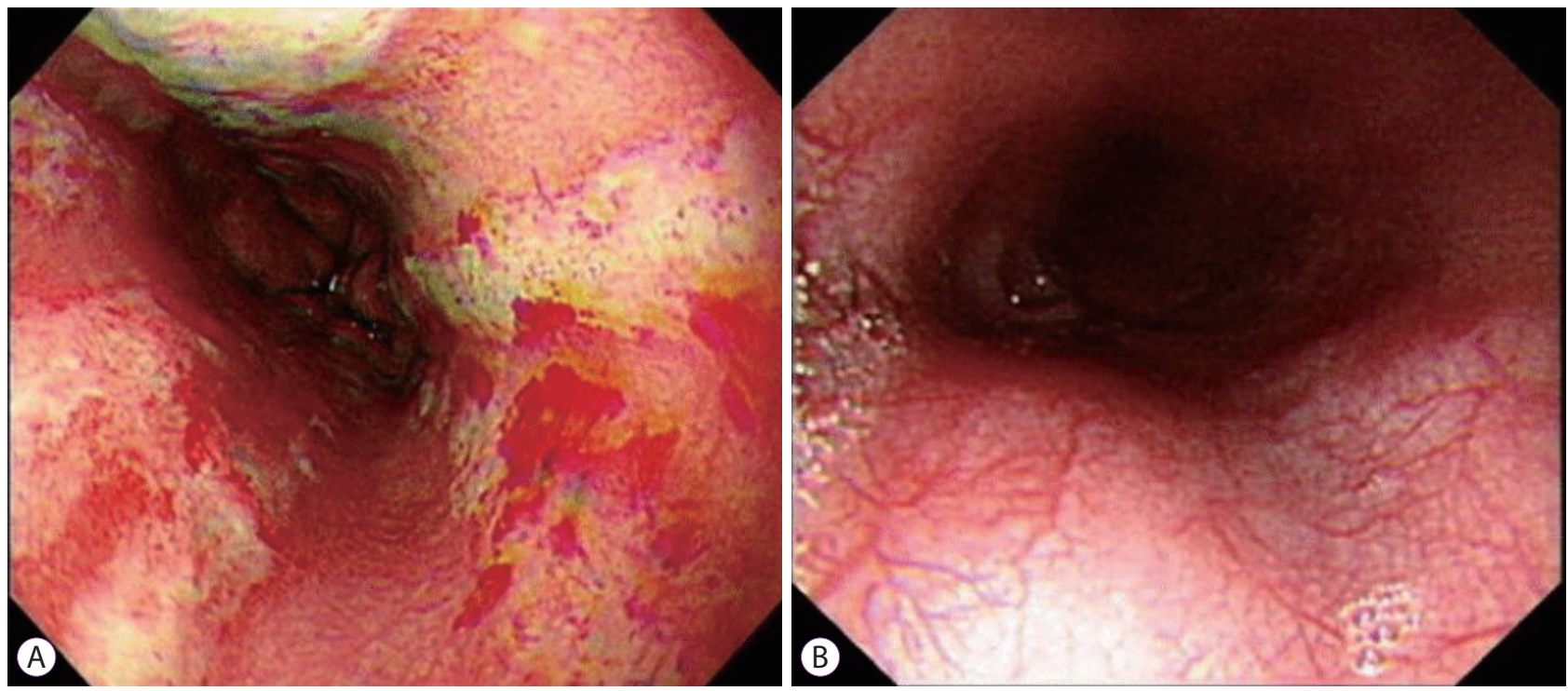

Fig. 2. Esophagoscopic findings of the patient. The initial esophagoscopy showed multiple longitudinal ulcers with concurrent mucosal hemorrhage and denuded mucosa in the whole esophagus (A). The follow-up esophagoscopy showed that the previous esophageal injuries were completely resolved (B). 
showed complete resolution of the esophageal mucosal lesions (Fig. 2B).

\section{DISCUSSION}

There have been many case reports concerning gastroesophageal damage induced by accidental drinking of a strong acid or strong alkali; however, reports on esophageal injury due to the consumption of a commercial vinegar beverage are very rare, especially in Korea. Various vinegar beverages are available in the market, usually with a $\mathrm{pH}$ below 5.5 , which indicates that such beverages are weak acids, but can cause corrosive damage to the digestive tract. The upper gastrointestinal tract regions, such as the esophagus and cardia, are especially vulnerable. ${ }^{2}$

There have been few reports on oral and esophageal injuries due to ingestion of vinegar-containing foods. Hill et al. performed an analysis on the acid components of various popular apple cider vinegar tablets available in US markets and esophageal injury due to specific brands. ${ }^{1}$ The report explained that esophageal injury can be induced based on the contact time length and the $\mathrm{pH}$, ingested volume, acid concentration, and form of the vinegar. It has been reported that the acid concentration of most commercial vinegar tablets was 3 to 10 -fold that of house vinegar. ${ }^{1}$ On the contrary, it was very difficult to find reports concerning acid components and any possible gastrointestinal injuries caused by commercial acidic beverages in Korea. Due to the increasing awareness regarding health, vinegar drinks are drawing attention as a health solution in everyday diet, though there has been no definite clinical evidence. Owing to its acidity, overconsump- tion of vinegar drinks may damage the gastrointestinal tract. We are not aware of the possibility of any hazards induced by household acidic foods. However, there has been a report of topical cutaneous contact with household apple cider vinegar, which had an acidity of less than $5 \%$, that resulted in abrupt epidermal necrosis in a 7-year-old boy. ${ }^{3}$

The stomach mucosa is more vulnerable to acid than the esophagus due to the protective esophageal eschar formation that allows acid to flow rapidly to the stomach. On the contrary, the high surface tension of alkali permits the esophagus to remain in contact with such ingested alkaline substances for longer periods, which can result in severe mucosal injury to the esophagus. ${ }^{4}$ The beverage our patient consumed was not strongly acidic. However, he had consumed the liquid for more than a month and swallowed large volumes at a time every day. Therefore, we suggest that this commercial beverage, even though it has a weak acid component, might induce mucosal damage.

Ingestion of caustic substances may cause corrosive damage to the contact site, which can lead to eosinophilic necrosis, swelling, and hemorrhagic congestion in the early stages. ${ }^{5}$ Homan et al. reported prominent eosinophils in esophageal pathological findings of an 8-year-old boy who accidentally ingested a strong acid; ${ }^{6}$ these findings were also noted in the esophagus biopsy of the patient in this report. The injured mucosa tends to progressively change over time. The injured mucosa is covered by a leukocytic fibrinous layer during the initial stages after the injury, and fibroblasts replace the lesion with time. After 5 days, the lesion has fungal infection. If the symptoms are more severe and the lesions are wider, esophageal fungi may also be noted. ${ }^{5}$

In this case, cardia swelling was seen on the CT scan, which
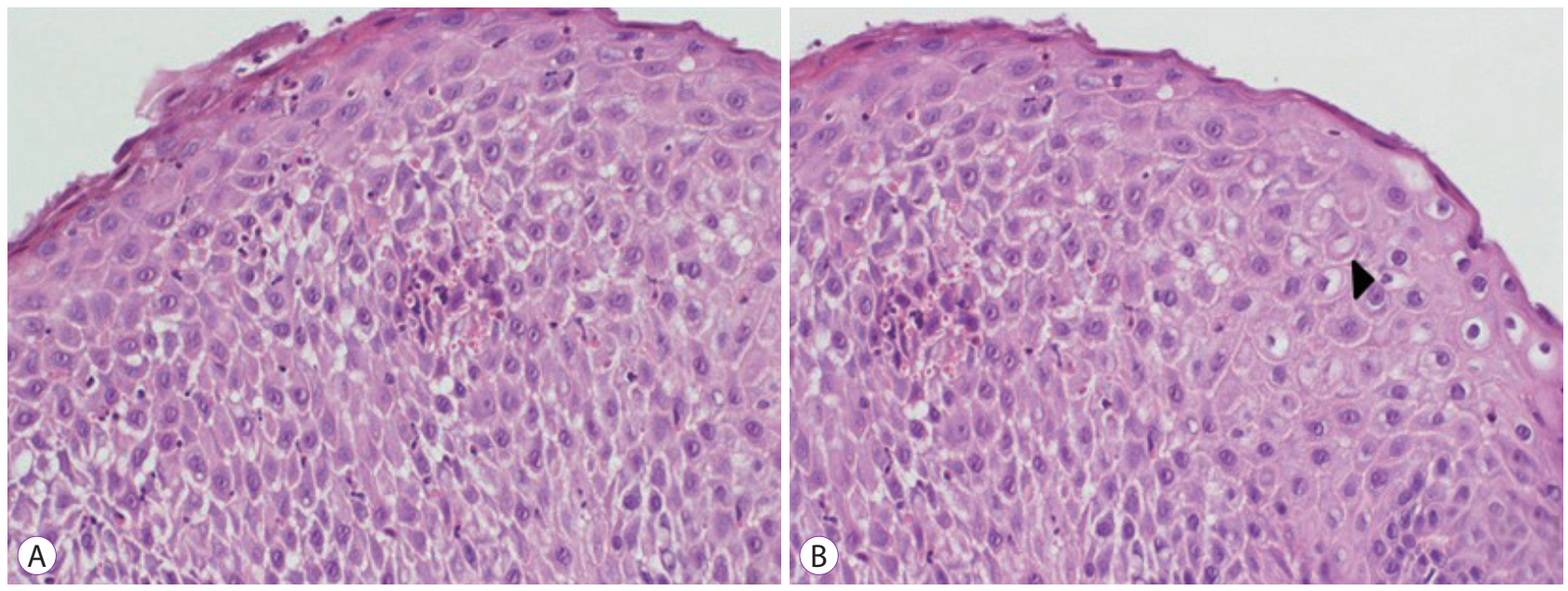

Fig. 3. Pathologic findings of the esophageal lesion. The esophageal biopsy showed minimal parakeratosis, some red blood cells (RBCs), and many eosinophilic infiltrates (A). Another section of the esophageal biopsy showed minimal parakeratosis, some RBCs, and many eosinophilic infiltrates (B). A neutrophil was also noted (arrow) (hematoxylin and eosin, $\times 400$ ). 
could not exclude the possibility of cardia damage due to corrosive esophagitis. On endoscopy, however, mucosal damage was directly observed, and only verrucous gastritis was observed in the cardia and upper gastric body, and acute mucosal changes such as ulcers were not observed. This patient had been treated for Helicobacter pylori-positive nodular gastritis and duodenal ulcer 1 year prior to the onset of corrosive esophagitis. H. pylori was not observed at the current presentation; however, chronic mucosal alteration due to $H$. pylori infection was suspected. Furthermore, the corrosive damage did not appear to extend to the cardia. This further emphasizes the importance of endoscopy for diagnosis in patients with corrosive esophageal injury.

Corticosteroid treatment is recommended to prevent the development of esophageal stricture. However, such treatments are controversial. A prospective study for 18 years on the effectiveness of corticosteroids as treatment for corrosive esophageal injury in children showed that there were no benefits of using corticosteroid treatment to prevent strictures. ${ }^{7}$ But there have been reports supporting the positive effects of corticosteroids in cases of corrosive esophagitis. A large study analyzing 361 subjects showed that esophageal stricture rarely occurred in the group treated with steroids and antibiotics; these data were statistically significant. ${ }^{8}$ High-dose methylprednisolone treatment for a short period is also effective to prevent esophageal stricture. ${ }^{9,10}$ This treatment can also be used effectively in patients with corrosive esophageal strictures and for those with resistance to dilatation therapy. ${ }^{11}$

In the past, nasogastric tubes were inserted to sustain patency of the esophageal lumen and to prevent esophageal stricture. ${ }^{12}$ However, it may also cause secondary injury due to vomiting while also causing acid reflux and long stenosis. ${ }^{13}$ This insertion routine is thus no longer recommended. ${ }^{12,13}$ On the other hand, the insertion of a nasogastric tube is helpful with respect to enteral feeding when esophageal injury is severe and oral intake is difficult. ${ }^{14}$ In a treatment algorithm for the ingestion of corrosive substances, enteral feeding via nasogastric tube is recommended in cases of circumferential lesions found via endoscopy. ${ }^{4}$

As shown in this case, vinegar beverages should be considered as corrosive agents that can cause serious gastrointestinal tract injury. Continuous consumption of vinegar beverages can cause acidic burns and destroy the surface of the upper gastrointestinal tract, leading to esophageal ulcers. Fruit-based fermented vinegar beverages are popular globally and are not strongly acidic, and their manufacturers take advantage of the impression that the drinks provide health benefits as a marketing strategy; however, we should be cautious while using such products because they can cause severe injury to the gastroesophageal mucosa.

Conflicts of Interest

The authors have no financial conflicts of interest.

\section{REFERENCES}

1. Hill LL, Woodruff LH, Foote JC, Barreto-Alcoba M. Esophageal injury by apple cider vinegar tablets and subsequent evaluation of products. J Am Diet Assoc 2005;105:1141-1144.

2. Chung $\mathrm{CH}$. Corrosive oesophageal injury following vinegar ingestion. Hong Kong Med J 2002;8:365-366.

3. Bunick CG, Lott JP, Warren CB, Galan A, Bolognia J, King BA. Chemical burn from topical apple cider vinegar. J Am Acad Dermatol 2012;67:e143-el44.

4. De Lusong MAA, Timbol ABG, Tuazon DJS. Management of esophageal caustic injury. World J Gastrointest Pharmacol Ther 2017;8:90-98.

5. Mamede RC, de Mello Filho FV. Ingestion of caustic substances and its complications. Sao Paulo Med J 2001;119:10-15.

6. Homan M, Orel R, Liacouras C. Caustic ingestion: a possible cause of eosinophilic esophagitis? Pediatrics 2013;131:e1284-e1287.

7. Anderson KD, Rouse TM, Randolph JG. A controlled trial of corticosteroids in children with corrosive injury of the esophagus. N Engl J Med 1990;323:637-640.

8. Howell JM, Dalsey WC, Hartsell FW, Butzin CA. Steroids for the treatment of corrosive esophageal injury: a statistical analysis of past studies. Am J Emerg Med 1992;10:421-425.

9. Usta M, Erkan T, Cokugras FC, et al. High doses of methylprednisolone in the management of caustic esophageal burns. Pediatrics 2014;133:E1518-E1524.

10. Yokota K, Uchida H, Tanano A, et al. Steroid pulse therapy prevents restenosis following balloon dilatation for esophageal stricture. Pediatr Surg Int 2016;32:875-879.

11. Divarci E, Celtik U, Dokumcu Z, Ozcan C, Erdener A. The efficacy of intralesional steroid injection in the treatment of corrosive esophageal strictures in children. Surg Laparosc Endosc Percutan Tech 2016;26:e122-e125.

12. Arunachalam R, Rammohan A. Corrosive injury of the upper gastrointestinal tract: a review. Archives of Clinical Gastroenterology 2016;2:5662.

13. Kochhar R, Poornachandra KS, Puri P, et al. Comparative evaluation of nasoenteral feeding and jejunostomy feeding in acute corrosive injury: a retrospective analysis. Gastrointest Endosc 2009;70:874-880.

14. Kluger Y, Ishay OB, Sartelli M, et al. Caustic ingestion management: world society of emergency surgery preliminary survey of expert opinion. World J Emerg Surg 2015;10:48. 